\title{
Phonological priming in spoken word recognition: Task effects
}

\author{
MONIQUE RADEAU, JOSÉ MORAIS, and AGNÈS DEWIER \\ Université libre de Bruxelles, Brussels, Belgium
}

\begin{abstract}
In two experiments, we examined the role of phonological relatedness between spoken items using both the lexical decision task and the shadowing task. In Experiment 1, words were used as primes and overlaps of zero (control), one, two, or all four or five (repetition) phonemes were compared. Except for the repetition conditions, in which facilitation was found, phonological overlap resulted in interference on word responses. These effects occurred in both tasks but were larger in lexical decision than in shadowing. The effects that were evident in shadowing can be attributed to an attentional mechanism linked to the subjects' expectancies of repetitions. The extra effects obtained in lexical decision can be interpreted by taking into account both activation of the response corresponding to the prime's lexical status and postlexical processes that check for phonological congruency between prime and target. In Experiment 2, some modifications were introduced to prevent the involvement of strategic factors, and pseudowords were used as primes. No effect at all was observed in shadowing, whereas in lexical decision interference effects occurred, which is consistent with the hypothesis that lexical decision may be negatively affected by finding a phonological discrepancy at the same time as the primed response is reactivated. Neither experiment provided evidence for the occurrence of phonological priming in the perceptual processing of words.
\end{abstract}

By definition, phonological priming refers to effects on word target recognition that arise from some phonological relationship between a prime and the target. As far as spoken words are concerned, phonological priming has come to be examined only in the last several years (Slowiaczek, Nusbaum, \& Pisoni, 1987; Slowiaczek \& Pisoni, 1986). This late interest is not surprising, since only recently did scholars realize that the study of spoken word recognition could provide a valid contribution, beside that of word reading, to the understanding of issues such as lexical access and the internal organization of the lexical system (see Frauenfelder \& Tyler, 1987).

Phonological priming could occur in spoken word recognition by means of at least two different mechanisms. First, activation of the lexical entry associated with the prime could spread to other, phonologically similar, lexical entries. Second, one can assume that some kind of component phonological representations (syllables, phonemes, or some portion of phonetic information) are involved in establishing the contact between the input and the corresponding lexical entry; activation of those

This work was supported in part by the Fund for Joint Basic Research under Convention 2.4531.88, and by the Ministry of Scientific Policy (National Incentive Program for Fundamental Research in Artificial Intelligence). The first author is a Research Associate of the National Fund for Scientific Research (Belgium). Edgar Fonck contributed to the software and hardware developments. We wish to thank Alain Content for fuitful suggestions. Thanks are also due to the editor and two anonymous referees for their help in improving the present report. Correspondence may be addressed to Monique Radeau, Laboratoire de Psychologie expérimentale, Université libre de Bruxelles, 117 av A. Buyl, B1050 Brussels, Belgium. representations during the prime-recognition process could last long enough to facilitate the extraction of similar representations from a phonologically similar target, and therefore to facilitate recognition of the target. Indeed, the plausibility of these mechanisms warrants the exploration of phonological priming effects. These effects, if they were proved to occur, could afford an interesting tool for inquiries into spoken word recognition.

The evidence already reported on phonological priming is inconsistent. The original cohort model of lexical access (Marslen-Wilson \& Welsh, 1978) provided the theoretical framework for the study by Slowiaczek et al. (1987). In that model, spoken word recognition is considered as a real-time process optimally adapted to the sequential characteristic of speech transmission. The main assumptions are that a cohort of lexical candidates are first activated by the acoustic-phonetic information from the beginning of the word and that they drop out from the cohort when they no longer fit the accumulating information. Since deactivation probably takes some time (Marslen-Wilson \& Welsh, 1978, p. 56, state that the eliminated candidates "may remain activated for a short period thereafter"), the notion of cohort activation predicts phonological priming. Indeed, if the target is a member of the cohort initiated by the prime, residual activation of this cohort should facilitate target recognition to an extent that depends on the amount of phonological information that is common to the initial portions of the two items.

In the study by Slowiaczek et al. (1987), a monosyllabic word target (four-phoneme long) target masked with white noise at different signal-to-noise ratios was 
presented in isolation, as a control, or following an unmasked word prime that shared with the target zero, one, two, three, or all (four) initial phonemes. Except for the zero- and one-phoneme-overlap conditions, the probability of correct identification was greater in the conditions of phonological overlap than in the unprimed conditions, with the identical condition giving the highest score. This facilitation effect grew stronger as the listening conditions became worse. For the authors, these results are consistent with the cohort model.

In a second experiment, which was similar to the first one except that, on the one hand, the prime was always a pseudoword and, on the other hand, the prime and the target were never identical, phonological priming was also observed. The fact that phonological priming was obtained with a pseudoword prime is consistent with the cohort model. Indeed, since what matters is the residual activation of the cohort rather than the final perceptual interpretation of the prime, the effect should be independent of the lexical status of the prime. However, facilitation was found to be much smaller with a pseudoword than with a word prime and, in addition, it was significant only for the three-phoneme overlap. This led Slowiaczek et al. (1987) to suggest a more complex model incorporating both phonological and lexical activation.

Finally, in a third experiment, Slowiaczek et al. (1987) found that phonological priming was roughly the same when the phonological information common to the two items concerned the final part of the items rather than the initial part. Of course, this is inconsistent with the original version of the cohort model, which supposes that the cohort is progressively reduced from the beginning of the item. At any rate, according to Slowiaczek et al., their results show that sets of word candidates are activated during word recognition.

An alternative, and more trivial, (hence more embarrassing), explanation of the phonological priming effects obtained by Slowiaczek et al. (1987) would be that these effects reflect guessing rather than perceptual processing. Asked to identify words in noise, their subjects might have tried to guess the missing cues of the targets from those provided by the context (see Bradley \& Forster, 1987, for a discussion of the distinction between perception and guessing). This explanation might help us understand why the priming effect was much smaller with the pseudoword primes: having noticed that the primes were pseudowords and that the targets were words, the subjects would be less prone to use the context in this situation.

The results obtained by Slowiaczek and Pisoni (1986) in two lexical decision experiments also cast some doubt on the perceptual interpretation of Slowiaczek et al.'s (1987) findings. The material in the former study, although not the same, also consisted of monosyllabic, four-phoneme-long items. Primes and targets both included words and pseudowords in an unpredictable manner. Besides a repetition effect displayed when the prime and the target were identical, no phonological facilitation was observed even in the three-phoneme-overlap condi- tion. However, if there were some residual activation from the prime, it should have produced a facilitatory effect on response latency. Thus, the absence of phonological priming in the lexical decision study might be interpreted as supporting the guessing interpretation of the effects obtained on identification in noise.

This is not the interpretation proposed by Slowiaczek and Pisoni (1986). According to them, postaccess processes prevented phonological priming effects from appearing in the lexical decision task. Indeed, this task probably involves substantial processing subsequent to lexical access, namely "meaning integration" (Forster, 1981) or "post-lexical coherence checking" (de Groot, 1985). Meaning integration refers to the fact that the decisionmaking mechanism takes into account not only the output of the lexical processor but also the semantic constraints derived from the context (a previous word, an embedding sentence, etc.). However, it is reasonable to suppose that the decision-making mechanism also takes into account whatever kind of relationship occurs frequently in the experimental situation. As Slowiaczek and Pisoni pointed out, an argument in favor of the intervention of a congruency checker for formal relationship comes from the data obtained by Jakimik, Cole, and Rudnicky (1985) in a study using the lexical decision task on spoken words. Jakimik et al. found a facilitatory effect for monosyllabic word targets preceded by bisyllabic word primes in conditions in which the common syllable was both phonologically and orthographically similar (e.g., MESSAGE-MESS). Phonological similarity alone (e.g., DEFINITE-DEAF) had no effect. The finding that spelling affects lexical decision-making on spoken words suggests that postperceptual assessment of graphemic congruency between prime and target was involved.

The available bulk of evidence on phonological priming is, thus, far from clear. One possibility is that phonological priming is a truly perceptual phenomenon which is disclosed by the task of perceptual identification in noise but hidden by postaccess processes contained in the lexical decision task. The opposite possibility is that phonological priming has no perceptual reality and that in the identification task in noise, the effect obtained actually results from guessing. Note that the two studies used different dependent variables (accuracy vs. response latency). This renders a global interpretation especially difficult.

What is needed is a task which involves lexical processing and which, like the naming task often used in studies on written word recognition, is relatively uncontaminated by postlexical processes. One such task may be shadowing. Its ability to reflect lexical processing was first suggested by Marslen-Wilson (1985), who presented evidence for effects of word frequency and lexical status on the shadowing latencies of isolated words. However, these effects were obtained by distant shadowers but not by close ones, thus suggesting that lexical access is not obligatory. Moreover, Balota and Chumbley (1985) have convincingly demonstrated that frequency may influence more 
than lexical access in the task of written word pronunciation, and the same might be true for the shadowing task. In a similar vein, as far as the lexicality effect is concerned, it is possible that, during the search or the activation of the phonological output representations for shadowing, words have an advantage simply because they involve more commonly used representations than do pseudowords. Recently, however, we have found less ambiguous evidence of lexical access in isolated word shadowing. In our study (Radeau \& Morais, 1989). shadowing latencies of trisyllabic words were highly correlated with the location of the uniqueness point, and within a range of relatively early locations this was true even for close shadowers. Indeed, this result implies that subjects cannot avoid consulting the mental lexicon in the shadowing task, at least on most occasions. Notice that we obtained an effect of the uniqueness point for long words in spite of the fact that for these words, a nonlexical strategy can, in principle, provide the motor articulatory program more quickly than can one involving lexical access.

Since the aim of the present study was to assess whether there is phonological priming facilitating the perceptual identification of a word target, we used the shadowing task. At a normal signal-to-noise ratio, this task should be minimally affected by guessing. Given the interest in assessing the contribution of postlexical processing, we also used the lexical decision task. Comparison of these two tasks is warranted by the fact that the same dependent variable-namely, response latency-is measured in both. In addition, to allow task comparison, we used exactly the same material for both tasks.

Shadowing and lexical decision were used with different groups of subjects in both Experiment 1 and Experiment 2. Experiment 1 included conditions of onephoneme, two-phoneme (one-syllable), and four- or fivephoneme (repetition) overlap. Given the possible influence of the occurrence of repetitions on some of the results observed, in Experiment 2 a three-phoneme-overlap condition was substituted for the repetition condition. There were other differences between the two experiments, which will be justified in the Discussion section of Experiment 1 .

\section{EXPERIMENT 1}

\footnotetext{
Method

Subjects. Forty-eight subjects, 21 males and 27 females, were tested on the lexical decision task. Twenty-four subjects, 11 males and 13 females, were tested on the shadowing task. All subjects were native French speakers and reported no hearing defects. Most were students at the University.

Material. A set of 12 words and 12 pseudowords, beginning with a stop consonant, served as targets. All were bisyllabic and had a $\mathrm{CV} / \mathrm{CV}$ or a $\mathrm{CV} / \mathrm{CVC}$ structure, with the first syllable always corresponding to the first $\mathrm{CV}$ cluster. Each of the six stop consonants occurred twice as the initial phoneme in each kind of target. Mean frequency of word targets, estimated in terms of relative frequen-
}

cies for the second half of the 20th century (Trésor de la Langue Française, 1971) was 2,659 (range 229-7,708)

Twelve sets of four bisyllabic words served as primes. A set of primes involved the four following types of items: (1) one of the 12 word targets (e.g., /paryr/, i.e., PARURE), (2) a word begin ning with the same syllable as Prime 1 (e.g., /pale/, i.e., PALAIS), (3) a word beginning with the same initial phoneme as Prime 1 and ending with the same syllable as Prime 2 (e.g., /pule/, i.e., POULET), and (4) a word obtained by replacing the first phoneme of Prime 3 with a consonant other than a stop consonant (e.g., /rule/, i.e., ROULER). Each prime of a set was paired separately with both a word and a pseudoword target. For word targets (e.g., /paryr/) pairing with Prime 1 gave rise to a repetition trial, with Prime 2 to a one-syllable-overlap trial, with Prime 3 to a onephoneme-overlap trial, and with Prime 4 to a zero-overlap trial that served as control trial. For pseudoword targets (e.g., /puty/), the design did not allow us to construct repetition trials, but onephoneme-overlap trials instead. Negative trials thus involved two conditions of one-phoneme overlap resulting from the pairing with Primes 1 or 2. Pairing with Prime 3 gave rise to a one-syllableoverlap trial and with Prime 4 to a zero-overlap or control trial. Thus, the test consisted of 96 pairs of trials. Thirty-two additional pairs of items without any relationship between them were selected to serve as practice trials

Procedure. The items were recorded by a female native speaker of French in a soundproof room. They were spoken neutrally at the rate of one item every $6 \mathrm{sec}$, using a Neumann U-87 microphone and a Studer A-810 tape recorder. Each item was pronounced once and was then copied on a two-track work tape at the different places where it was to occur as a prime or a target. The primes were recorded on the first channel and the targets on both channels. The stimulus-onset asynchrony was $700 \mathrm{msec}$. It outlasted to the least extent the duration of the longest primes.

Presentation of the items and collection of data were controlled by an Apple Ile computer connected to a Revox A77 tape recorder. During testing, the onset of the target recorded on the second channel released a voice key connected to a clock-card (Apple clock Mountain Hardware)

Subjects were tested individually in a quiet room. They heard the stimuli at a comfortable level through Beyer DT-202 headphones. They were told that the first item of the pairs would always be a word and were asked to respond only to the second item.

In the lexical decision task, the subjects were asked to respond (word or pseudoword) by pushing one of the two pushbuttons interfaced to the computer via the game connector. In the shadowing task, they were asked to repeat back the second item. In both tasks, they were asked to respond as quickly and accurately as possible.

The 96 pairs of experimental items were presented in four blocks of trials in balanced order. Each target occurred once in a block and each type of trial occurred three times in each block in random order. The session began with a block of practice trials. The trials followed each other at a rate of one every $8 \mathrm{sec}$.

\section{Results}

Reaction times (RT) longer than $1,400 \mathrm{msec}$ or shorter than $200 \mathrm{msec}$ and incorrect responses were discarded from the analysis. For the shadowing task, a response was considered incorrect if there was any deviation of at least one phoneme relative to the presented item. For each overlap and each type of target, mean RTs and error rates were calculated for each subject across items and for each item across subjects.

Lexical decision. Mean RTs and error rates for the different overlaps are presented in Table 1 separately for 
Table 1

Mean RTs (in msec) and Error Rates (\%) in the Lexical Decision Task of Experiment 1

\begin{tabular}{|c|c|c|c|}
\hline Overlap & RT & $\begin{array}{l}\text { Error } \\
\text { Rate }\end{array}$ & Priming \\
\hline \multicolumn{4}{|c|}{ Word Targets } \\
\hline Control & 672 & 3.6 & \\
\hline 1 Phoneme & 711 & 5.9 & -39 \\
\hline 1 Syllable & 716 & 2.4 & -44 \\
\hline Repetition & 576 & 2.6 & 96 \\
\hline \multicolumn{4}{|c|}{ Pseudoword Targets } \\
\hline Control & 729 & 2.8 & \\
\hline 1 Phoneme & 714 & 3.4 & 15 \\
\hline 1 Syllable & 745 & 3.5 & -16 \\
\hline
\end{tabular}

word and pseudoword targets. Regarding phonological overlap, the main result is that it gave rise to interference on word responses, except for repetition trials, where a strong facilitatory effect is evident.

Mean RTs per subject and per item were analyzed separately for words and pseudowords by ANOVAs with overlap (four or three levels, respectively, for words and pseudowords) as a fixed-levels factor. For word targets, the effect of overlap was significant in both analyses [subjects, $F(3,141)=204.25, M S_{\mathrm{e}}=998.2, p<.005$; items, $F(3,33)=52.64, M S_{\mathrm{e}}=955.2, p<.005$ ]; for pseudoword targets, it was significant in the analysis by subject $\left[F(2,94)=14.03, M S_{\mathrm{e}}=824.3, p<.005\right]$ but not in the analysis by item $\left[F(2,22)=2.62, M S_{\mathrm{e}}=873.7\right.$, $p>.10]$.

Planned comparisons were conducted to test for the effects of the different overlaps on each type of target. For word targets, the facilitatory effect of repetition was significant in both analyses [subjects, $F(1,47)=200.72, M S_{\mathrm{e}}$ $=1,112.9, p<.005$; items, $F(1,11)=74.13, M S_{\mathrm{e}}=$ $769.4, p<.005$ ]. The interference effects obtained in the one-syllable- and in the one-phoneme-overlap trials were significant by subject [one-syllable, $F(1,47)=$ $52.17, M S_{\mathrm{e}}=917.7, p<.005$; one-phoneme, $F(1,47)$ $=45.87, M S_{\mathrm{e}}=776.3, p<.005$ ] and by item [onesyllable, $F(1,11)=25.44, M S_{\mathrm{e}}=390.3, p<.005$; onephoneme, $\left.F(1,11)=14.60, M S_{\mathrm{e}}=624.2, p<.005\right]$ and did not differ from one another (both $F$ s close to 0 ). For pseudoword targets, the interference effect of the onesyllable overlap and the facilitatory effect of the onephoneme overlap were significant in the analysis by subject [one-syllable, $F(1,47)=4.48, M S_{\mathrm{e}}=1,264.4$, $p<.05$; one-phoneme, $F(1,47)=10.11, M S_{\mathrm{e}}=582.6$, $p<.005]$ but not in the analysis by item.

The effect of lexicality (word vs. pseudoword) was assessed in a third pair of ANOVAs with two levels of overlap (control and one-syllable-overlap trials). Subjects responded to words faster than to pseudowords. This effect, which is classically found in lexical decision studies, was significant in the analysis by subject $[F(1,47)=$ $\left.24.99, M S_{e}=3,913.9, p<.005\right]$ and fell short of significance in the analysis by item $\left[F(1,22)=3.94, M S_{\mathrm{e}}\right.$ $=6,036.2, p<.10]$. The overlap $\times$ lexicality interaction was significant in both analyses [subjects, $F(1,47)=$ $12.19, M S_{\mathrm{c}}=843.9, p<.005$; items, $F(1,22)=4.40$, $\left.M S_{\mathrm{c}}=546.8, p<.01\right]$. In control trials, lexicality was significant both by subject $\left[F(1,47)=34.11, M S_{\mathrm{c}}=\right.$ $2,515.3, p<.005]$ and by item $\left[F(1,22)=6.79, M S_{c}\right.$ $=3,041.1, p<.025]$, whereas in one-syllable-overlap trials, it was significant by subject $\left[F(1,47)=9.95, M S_{\mathrm{e}}\right.$ $=2,242.6, p<.005]$ but not by item $(F$ close to 1$)$.

The ANOVAs run on error rates did not reveal any significant effect or interaction.

Shadowing. Mean RTs and error rates are presented in Table 2. The results are in the same direction as those obtained with the lexical decision task. Repetition gave rise to facilitation and partial phonological overlap resulted in interference on word targets. These effects, however, were much smaller than those in the lexical decision task. Latencies of word responses were faster than those of pseudoword responses.

ANOVAs run on RTs for word targets with overlap (four levels) as a fixed-levels factor revealed a significant effect of overlap [subjects, $F(3,81)=17.29, M S_{\mathrm{e}}=$ $561.3, p<.005$; items, $F(3,33)=16.18, M S_{\mathrm{e}}=256.7$, $p<.005]$. The facilitatory effect of repetition was significant in both analyses [subjects, $F(1,27)=8.33, M S_{\mathrm{e}}$ $=908.2, p<.005$; items, $F(1,11)=8.32, M S_{\mathrm{e}}=$ $386.8, p<.01]$. The interference resulting from partial phonological overlap was significant in the one-syllableoverlap trials both by subject $\left[F(1,27)=16.41, M S_{\mathrm{e}}=\right.$ $373.5, p<.005]$ and by item $\left[F(1,11)=10.34, M S_{\mathrm{e}}\right.$ $=259.9, p<.01]$. In the one-phoneme-overlap trials, it did not reach significance [subjects, $F(1,27)=2.91$, $M S_{\mathrm{e}}=338.3, p>.10$; items, $F(1,11)=3.11, M S_{\mathrm{e}}=$ $120.7, p>.10]$. In the ANOVAs run on RTs for pseudoword targets, overlap (three levels) was not significant ( $F$ close to 1 and 0 for subjects and items, respectively.

ANOVAs run on the RTs of control and one-syllableoverlap trials for both words and pseudowords showed that the lexicality effect was significant by subject $[F(1,27)$ $\left.=70.68, M S_{\mathrm{e}}=402.5, p<.005\right]$ but not by item $\left[F(1,22)=2.61, M S_{\mathrm{e}}=4,835.1, p>.10\right]$. The overlap $\times$ lexicality interaction was significant in both analyses [subjects, $F(1,27)=24.28, M S_{\mathrm{e}}=190.0, p<.005$;

Table 2

Mean RTs (in msec) and Error Rates (\%) in the Shadowing Task of Experiment 1

\begin{tabular}{|c|c|c|c|}
\hline \multirow[b]{2}{*}{ Overlap } & \multicolumn{3}{|c|}{ Error } \\
\hline & RT & Rate & Priming \\
\hline \multicolumn{4}{|c|}{ Word Targets } \\
\hline Control & 616 & 1.5 & \\
\hline 1 Phoneme & 625 & 0.9 & -9 \\
\hline 1 Syllable & 637 & 1.2 & -21 \\
\hline Repetition & 593 & 0.6 & 23 \\
\hline \multicolumn{4}{|c|}{ Pseudoword Targets } \\
\hline Control & 661 & 3.9 & \\
\hline 1 Phoneme & 651 & 3.7 & 10 \\
\hline 1 Syllable & 656 & 2.1 & 5 \\
\hline
\end{tabular}


item, $\left.F(1,22)=4.62, M S_{e}=376.2, p<.025\right]$. In control trials, lexicality was significant both by subject $\left[F(1,27)=122.8, M S_{\mathrm{e}}=227.8, p<.005\right]$ and by item $\left[F(1,22)=4.85, M S_{\mathrm{e}}=2,445.9, p<.025\right]$. In onesyllable-overlap trials, it was significant by subject $\left[F(1,27)=13.91, M S_{\mathrm{e}}=364.7, p<.005\right]$ but not by item $(F<1)$.

Fewer errors were made by shadowing words than pseudowords. ANOVAs run on the data of control and one-syllable-overlap trials showed that the difference was significant by subject $\left[F(1,27)=4.50, M S_{\mathrm{e}}=0.3\right.$, $p<.005]$ and fell short of significance by item $[F(1,22)$ $\left.=4.12, M S_{\mathrm{e}}=0.6, p<.10\right]$. No other factor or interaction reached significance in the analyses of error rates.

ANOVAs taking into account the data of the two tasks, run separately on word data (four levels of overlap) and on pseudoword data (three levels of overlap), showed that the shadowing task yielded shorter response latencies than did the lexical decision task. This effect was significant both for words [subjects, $F(1,70)=7.89, M S_{\mathrm{c}}=$ $22,545.9, p<.005$; items, $F(1,11)=13.78, M S_{\mathrm{e}}=$ $4,153.5, p<.005$ ] and for pseudowords [subjects, $F(1,70)=14.55, M S_{\mathrm{e}}=19,041.7, p<.005$; items, $\left.F(1,11)=11.40, M S_{\mathrm{e}}=8,280.1, p<.005\right]$. For words, the interaction between task and overlap was significant both by subject $[3,210)=45.53, M S_{\mathrm{e}}=837.5$, $p<.005]$ and by item $[3,336)=22.25, M S_{\mathrm{c}}=613.6$, $p<.005]$. Except for repetition trials, in which RTs were not significantly different between the two tasks (both $F \mathrm{~s}$ close to 0 ), the differences were significant for each overlap [one-phoneme, $F(1,70)=16.71 . M S_{\mathrm{e}}=6,401.8$, $p<.005$ for subjects, and $F(1,11)=40.62, M S_{\mathrm{e}}=$ $1,067.0, p<.005$ for items; one-syllable, $F(1,70)=$ $21.60, \mathrm{~m} M S_{\mathrm{e}}=5,902.2, p<.005$ for subjects, and $F(1,11)=33.990, M S_{\mathrm{e}}=1,024.3, p<.005$ for items; control, $F(1,70)=8.72, M S_{\mathrm{e}}=6,043.3, p<.005$ for subjects, and $F(1,11)=20.04, M S_{\mathrm{e}}=881.0, p<.005$ for items]. For pseudowords, the interaction between overlap and task was significant by subject $[F(2,140)=$ $\left.4.52, M S_{\mathrm{e}}=673.8, p<.025\right]$ but not by item $(F$ close to 1$)$. RTs by subject were shorter in the shadowing than in the lexical decision task in all conditions of overlap [one-phoneme, $F(1,70)=10.28, M S_{\mathrm{e}}=6,743.29$, $p<.005$; one-syllable, $F(1,70)=18.82, M S_{\mathrm{e}}=7,140.4$, $p<.005$; control, $F(1,70)=12.18, M S_{\mathrm{e}}=6,505.8$, $p<.005]$. For error rates, the shadowing task yielded fewer errors on word responses than did the lexical decision task [subjects, $F(1,74)=13.82, M S_{e}=0.5$, $p<.005$; items, $F(1,11)=10.15, M S_{\mathrm{e}}=5.1$, $p<.01$ ], and the two tasks did not differ regarding pseudoword responses ( $F$ close to 0 and 1 for subjects and items, respectively). Neither for words nor for pseudowords did the effect of overlap or the interaction between overlap and task reach significance in the analyses of error rates.

\section{Discussion}

No phonological facilitation was observed on word targets either in shadowing or in lexical decision, except for the repetition condition (i.e., when the prime and the target were identical). This repetition effect has been reported several times with spoken words (Ellis, 1982; Jackson \& Morton, 1984; Slowiaczek et al., 1987; Slowiaczek \& Pisoni, 1986) and cannot be attributed specifically to phonological priming: it could be due exclusively, or partly, to lexical priming. Consistent with this view, it is worth noting that in the lexical decision experiments of Slowiaczek and Pisoni (1986), only the repetition condition gave rise to a facilitation effect, and that, in the identification in noise experiments of Slowiaczek et al. (1987), the facilitation effect observed in the repetition condition was much greater than those observed in the other conditions.

In both tasks, partial phonological overlap led to an interference effect on the response toward targets. This interference, as well as the facilitatory effect of repetition, was much larger in lexical decision than in shadowing. The most reasonable way to account for this pattern of results is to consider that two different mechanisms were at work. One of them would be attentional and prelexical; it would be responsible for the part of the effects that occur in the shadowing task. The other mechanism might be automatic and postlexical; it would account for the extra effects obtained in the lexical decision task.

The former mechanism might be the attentional process proposed by Posner and Snyder (1975), and demonstrated by Neely (1977) to be another source of priming besides automatic spreading activation. Since this mechanism is assumed to operate prior to target recognition, it should affect the response to the same extent in both tasks. According to Posner and Snyder's theory, conditions of high predictability of prime-target relationships would allow the subject to formulate expectations about the target from the prime. In the present situation, having noticed the existence of repetition trials, the subject would tend to anticipate a repetition from the moment he/she has identified in the target an initial phoneme or syllable that was identical to the initial part of the prime. In partial phonological overlap trials, processing of the remainder of the target would lead the subject to revise his/her prediction, which of course takes some time and would slow down the response. In repetition trials in which the prediction is correct, the response could be given faster. Let us note that although the attentional mechanism may account for the whole repetition effect obtained with the shadowing task, this effect may also be attributed, at least in part, to persistence of activation of the recognition unit for the repeated word, as in Morton's (1970) logogen model.

The difference in the size of facilitation and inhibition effects between lexical decision and shadowing seems to result from processes that, unlike attentional mechanisms, are not under strategic control and start to operate after both the prime and the target have been recognized. There is a lot of evidence that these processes are maximized in binary choice tasks such as lexical decision (de Groot, 1985; Forster, 1981; Lorch, Balota, \& Stamm, 1986; Seidenberg, Waters, Sanders, \& Langer, 1984). Shadowing, as well as naming, probably involves decision 
processes to a lesser extent than does lexical decision and is thus expected to be less affected by postrecognition components.

In the present situation, it may be assumed that postaccess processes, which check for phonological congruency between the prime and the target, were involved and biased the response of the decision-making mechanism in the lexical decision task. The subject has no reason to prepare him- or herself to respond to either a word or a pseudoword but, having obligatorily recognized the prime (one cannot avoid perceiving speech inputs), he/she has probably assigned a lexical status to it, and this assignment, though irrelevant to the task, may activate the corresponding response. Thus, in the present experiment, in which the prime was always a word, the subject was primed to respond to a word. And if the target is actually a nonword, the decision-making mechanism has to switch from the prepared to the unprepared response. The important point is that in most trials, there is also some phonological relationship between the prime and the target. Presumably, the activation, from the very beginning of the processing of the target, of the same phonological information that had been activated by the prime triggers a phonological congruency checker. This checker provides redundant information, and may thus be useful, if the target and the prime are phonologically identical (i.e., in repetition trials). By contrast, in the partial overlap conditions, its outcome is completely irrelevant to the task. However, the fact that in these conditions, phonological congruency checking leads to a negative outcome may place the decision-making mechanism in a transient state of uncertainty. As a matter of fact, in word trials, this mechanism is informed both that the prepared response is appropriate and that there is a phonological discrepancy. It is in some sense like being told both yes and no. The decision-making mechanism might then need some extra time to discard the importunate "no" as irrelevant and, perhaps, to verify the assignment of lexical status to the target. The mechanism we propose is thus of a Stroop sort. No such inhibition would occur in nonword trials, since noticing a phonological descrepancy does not appear to contradict the indication to respond in the way opposite to the prepared response. No such inhibition would occur in control trials, either, since the presence of completely different phonological information at the beginning of the target and of the prime probably does not justify the operation of a congruency checker. Congruency checking may make sense when pursuing an old track, but not when opening a new one.

The inhibition generated in word trials by the partial overlap of phonological information would be added in some manner to the inhibition due to a subject's expectancy of repetition in the lexical decision task but, of course, not in the shadowing task. As a matter of fact, inhibition effects were much smaller in the latter task. In repetition trials, the phonological reinforcement of the prepared response would enhance the facilitating effect of repetition in the lexical decision task relative to the shadowing task. Consistent with this view, the repetition effect was larger in the former task. The present interpretation does not account for the facilitation and interference effects that occur, respectively, in the phoneme- and the syllable-overlap trials for pseudoword responses in the lexical decision task. But note that both of these effects were nonsignificant in the analysis by item and should thus be considered with caution.

The postlexical mechanism hypothesized above is indeed rather complex and should be tested. One way of testing it is to use pseudowords as primes. In that case, partial phonological overlap is expected to result in inhibition for pseudoword rather than word responses, since for words, the negative output of the phonological checking probably will not add anything to the necessity of a shift from the prepared pseudoword response, whereas for pseudowords, confirmation of the primed response will be counteracted by the phonological discrepancy. Thus, in Experiment 2 pseudowords were used as primes.

To avoid effects due to subjects' expectancies of repetitions, in Experiment 2 a three-phoneme-overlap type of trials was substituted for the repetition trials; and to reduce the expectancy of phonological similarity, a significant number of filler trials were incorporated. These two modifications were intended to prevent a possible effect of phonological facilitation from being hidden by strategic factors, especially in the shadowing task. Moreover, if checking the phonological congruency between the target and the prime is induced merely by the presence of repetition trials, which may make it a useful strategy, inhibition effects should not be observed in Experiment 2. But if it is triggered automatically by the existence, however irrelevant to the task, of a partial phonological overlap, then inhibition effects should survive the lack of repetition trials.

Finally, to avoid strengthening the association between response and target, in Experiment 2, each target was presented only once and not four times as in Experiment 1 .

\section{EXPERIMENT 2}

\section{Method}

Subjects. Thirty-two subjects were tested on each task. Twentyone fernales and 11 males participated in the lexical decision task, and 20 females and 12 males participated in the shadowing task. These subjects fulfilled the same criteria as those of Experiment 1.

Material. A total of 720 pairs of items, of which 640 served as critical pairs ( 160 of these were heard by any one subject) and the other 80 (presented to every subject) served as fillers, were used in this experiment. All items were bisyllabic, four phonemes long, and had a CV/CV structure. Mean frequency of word targets was 3,704 , with frequencies ranging from 0 to 15,692 (Trésor de la Langue Française, 1971).

The targets of the critical pairs consisted of 80 words and 80 pseudowords. For each target, four pseudoword primes were constructed: (1) beginning with the same initial phoneme, (2) with the same first two phonemes (i.e., the same first syllable), (3) with the 
same first three phonemes, and (4) without any phoneme in common. Prime 3 was constructed by changing the last vowel of the target, Prime 2 by changing the second consonant of Prime 3 , and Prime 1 by changing the second vowel of Prime 2. Prime 4 began with the last syllable of Primes 1 and 2. For example, the primes associated with the word target /roti/ (i.e., ROTI) were (1) /ramy/. (2) /romy/, (3) /roty/, and (4) /myna/, and those associated with the pseudoword target/zuta/ were (1)/zine/, (2) /zune/, (3) /zute/, and (4) /nepi/. Trials involving Prime 1,2, or 3 will be referred to as 1-, 2-, or 3-phoneme-overlap trials, and those involving Prime 4 will be referred to as control trials.

Care was taken that the phonologically overlapping part of the items was also orthographically similar. Only primes in which the spelling of this overlapping part corresponded to that of the target were used. The selection was made by submitting the items for dictation to an independent sample of subjects and by excluding the items with ambiguous spellings.

Eighty filler pairs with no phoneme in common were constructed, half with words and half with pseudowords as targets. An additional set of 30 unrelated pairs served for practice.

Procedure. The recording and presentation of the items, as well as the collection of data, were the same as in Experiment 1 except that the stimuli were recorded by a male native speaker of French and the stimulus-onset asynchrony was $850 \mathrm{msec}$ long, outlasting to a slight extent the duration of the longest primes.

The 640 critical pairs were divided into four sets. Each set was heard by a group of 8 subjects so that a subject never heard the same target on any of the trials of the experiment. In each set, all of the targets were presented once and each type of overlap occurred the same number of times. In order for related and unrelated pairs to occur equally often, the items of the filler pairs were all presented to each subject. A subject was thus presented with 160 pairs of critical items, of which 120 were related and 40 were unrelated, and with 80 pairs of (unrelated) fillers. These 240 pairs of items were divided into four blocks with order of presentation balanced within each group of subjects

The order of presentation of the pairs within a block was determined randomly, with the restriction that the same response did not occur more than three times consecutively and that no more than two pairs with the same type of overlap followed one another.

The subjects were instructed that the first item of the pairs would always be a pseudoword. As in Experiment 1, they were asked either to perform a lexical decision task on the second item or to repeat back this item.

The experiment lasted for about $45 \mathrm{~min}$ and was completed in one session.

\section{Results}

The data were analyzed according to the same criteria as those of Experiment 1. ANOVAs with overlap and lexicality as factors were run on mean RTs and error rates by subject and by item. The fillers were included in the analyses treating the data by subject but not in those by item, leading, respectively, to five and four levels of overlap.

Lexical decision. The most striking difference between the results of this experiment (see Table 3) and those of Experiment 1 is that now interference effects concerned pseudoword rather than word responses.

ANOVAs run on RTs showed a significant effect of lexicality [subjects, $F(1,31)=143.61, M S_{\mathrm{e}}=3,329.7$, $p<.005$; items, $F(1,158)=34.54, M S_{e}=28,085.4$, $p<.005]$ and a significant interaction between overlap and lexicality [subjects, $F(4,124)=6.73, M S_{\mathrm{c}}=1,222.3$,
Table 3

Mean RTs (in msec) and Error Rates (\%) in the Lexical Decision Task of Experiment 2

\begin{tabular}{lccr}
\hline \multicolumn{1}{c}{ Overlap } & RT & $\begin{array}{r}\text { Error } \\
\text { Rate }\end{array}$ & Priming \\
\hline Filler & \multicolumn{2}{c}{ Word Targets } & \\
Control & 714 & 6.6 & \\
1 Phoneme & 722 & 6.6 & 14 \\
1 Syllable & 708 & 5.3 & -13 \\
3 Phonemes & 735 & 5.9 & 20 \\
& 702 & 5.8 & \\
Filler & Pseudoword Targets & \\
Control & 782 & 1.8 & \\
1 Phoneme & 777 & 2.7 & -11 \\
1 Syllable & 788 & 4.4 & -27 \\
3 Phonemes & 817 & 3.4 & -40 \\
\hline
\end{tabular}

$p<.005 ;$ items, $F(3,474)=9.08, M S_{\mathrm{e}}=3,289.3$, $p<.005]$. For word targets, the effect of overlap was significant by subject $\left[F(4,124)=4.68, M S_{\mathrm{e}}=1,127.9\right.$, $p<.005]$ and by item $\left[F(3,237)=6.53, M S_{\mathrm{c}}=\right.$ $2,775.2, p<.005]$. Among the planned comparisons involving control trials, a significant effect was found only in the three-phoneme-overlap trials. This effect, however, was significant in the analysis by item $[F(1,79)=5.49$, $\left.M S_{\mathrm{e}}=2,834.0, p<.025\right]$ but not in the analysis by subject $\left[F(1,28)=2.58, M S_{\mathrm{e}}=2,339.3, p>.10\right]$. For pseudoword targets, the effect of overlap was significant in both analyses [subjects, $F(4,124)=6.34, M S_{\mathrm{c}}=$ $1,385.9, p<.005$; items, $F(3,237)=7.31, M S_{\mathrm{e}}=$ 3,803.5. $p<.005]$. The interference effects of the phonological overlap were significant in the two- and three-phoneme-overlap trials both by subject [twophoneme overlap, $F(1,31)=7.92, M S_{\mathrm{e}}=1,494.8$, $p<.01$; three-phoneme overlap, $F(1,31)=19.24, M S_{\mathrm{e}}$ $=1,355.8, p<.005]$ and by item [two-phoneme overlap, $F(1,79)=8.81, M S_{\mathrm{c}}=3,398.9, p<.01$; threephoneme overlap, $F(1,79)=17.39, M S_{\mathrm{e}}=4,349.9$, $p<.005]$. These effects did not differ significantly from one another. The comparison between the one-phonemeoverlap and the control trials fell short of significance. For pseudowords as well as for words, there was no significant difference between the filler and the control trials.

The analysis of mean error rates showed an effect of lexicality that was significant in the analysis by subject $\left[F(1,31)=11.26, M S_{\mathrm{e}}=1.4, p<.005\right]$ but not in the analysis by item $\left[F(1,158)=1.16, M S_{\mathrm{e}}=1.3, p>.10\right]$. The decrease in RTs for words was thus associated with a small increase in error rates. The interaction between overlap and lexicality was also significant [subjects, $F(4,124)=2.59, M S_{\mathrm{e}}=0.8, p<.05$; items, $F(3,474)$ $\left.=3.86, M S_{\mathrm{e}}=0.4, p<.01\right]$. This interaction was due to the fact that overlap had a significant effect on pseudoword responses [subjects, $F(4,124)=6.86, M S_{\mathrm{e}}=0.6$, $p<.005$; items $\left.F(3,237)=3.35, M S_{c}=0.3, p<.025\right]$ but not on word responses (both $F \mathrm{~s}<1$ ). For pseudoword responses, among the comparisons involving control 
trials, the three-phoneme-overlap trials were the only ones to yield a significant increase in error rate [subjects, $F(1,31)=7.52, M S_{\mathrm{e}}=0.8, p<.025$; items, $F(1,79)$ $\left.=6.86, M S_{\mathrm{e}}=0.5, p<.025\right]$.

Shadowing. Mean RTs and error rates in the shadowing task are presented in Table 4.

Contrary to what was observed in both Experiment 1 and the present lexical decision task, phonological overlap no longer produced any negative (or positive) effect. ANOVAs run on RTs revealed no effect of overlap (both $F$ s close to 1) and no interaction between overlap and lexicality ( $F$ close to 1 and 0 for subjects and items, respectively). Lexicality was the only significant main effect: as in Experiment 1, words were repeated back faster than were pseudowords, and this effect was significant both by subject $\left[F(1,31)=393.88, M S_{\mathrm{e}}=548.9, p<.005\right]$ and by item $\left[F(1,158)=18.45, M S_{\mathrm{e}}=26,589.0\right.$, $p<.005]$. The lexicality effect was also significant in the analysis of error rates [subjects, $F(1,31)=22.88, M S_{\mathrm{e}}$ $=0.27, p<.005$; items $F(1,158)=9.42, M S_{\mathrm{e}}=0.3$, $p<.005$ ]: words were shadowed more accurately than were pseudowords.

The comparison of the data coming from the two conditions provides the same pattern of results as that of Experiment 1. Response latencies were shorter in the shadowing than in the lexical decision task. This effect was significant by subject $\left[F(1,62)=11.11, M S_{\mathrm{e}}=\right.$ $37,486.7, p<.005]$ and by item $\left[F(1,158)=102.5, M S_{\mathrm{e}}\right.$ $=8,600.7, p<.005$ ]. It interacted with overlap [subjects, $F(4,248)=3.74, M S_{\mathrm{e}}=1,008.4, p<.005$; items, $\left.F(3,474)=4.48, M S_{\mathrm{e}}=3,088.6, p<.005\right]$ and lexicality [subjects, $F(1,62)=13.22, M S_{\mathrm{e}}=1,939.3$, $p<.005$; items, $F(1,158)=4.70, M S_{\mathrm{e}}=8,600.7$, $p<.005]$. The task $\times$ overlap $\times$ lexicality interaction was also significant [subjects, $F(4,248)=3.36, M S_{\mathrm{e}}=$ $1,301.7, p<.01$; items, $F(3,474)=4.32, M S_{\mathrm{e}}=$ $3,088.6, p<.005]$. The shadowing task yielded fewer errors than did the lexical decision task [subjects, $F(1,62)$ $=29.25, M S_{\mathrm{e}}=1.8, p<.005$; items, $F(1,158)=$ 37.14, $\left.M S_{\mathrm{e}}=0.6, p<.005\right]$. This effect interacted with lexicality [subjects, $F(1,62)=24.78, M S_{\mathrm{e}}=0.8$,

Table 4

Mean RTs (in msec) and Error Rates $(\%)$ in the Shadowing Task of Experiment 2

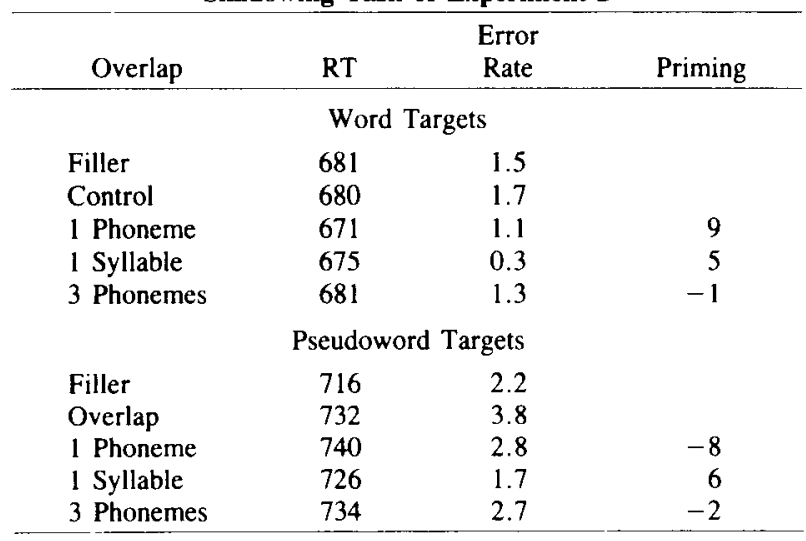

$p<.005$; items, $\left.F(1,158)=7.09, M S_{\mathrm{e}}=0.6, p<.01\right]$ and this interaction was due to the fact that the difference in error rates between the two tasks was greater for word than for pseudoword responses.

\section{Discussion}

As a consequence of some or all of the methodological changes introduced in Experiment 2 (absence of repetition trials, presence of fillers, pseudowords as primes, no repeated target), no effect at all of phonological relatedness was observed in the shadowing task, suggesting that, as proposed earlier, attentional factors were responsible for the effects obtained with the same task in Experiment 1 . On the other hand, in this task, a lexical status effect was again observed and it was as clear as in Experiment 1. Assuming, as we suggested in the introduction on the basis of further evidence (Radeau \& Morais, 1989), that shadowing responses are attained most of the time through lexical access, the present findings are contrary to the idea that phonological priming occurs during the perceptual processing of spoken words.

As far as lexical decision is concerned, it is worth noting that, as expected, interference effects due to partial phonological overlap were now observed on pseudoword responses, and not on word responses as in Experiment 1. This corroborates the hypothesis put forward in the Discussion of Experiment 1, according to which some inhibition could arise from finding a phonological discrepancy between the target and the prime at the same time as the primed response is reactivated. Furthermore, the fact that interference effects were observed in the absence of repetition trials suggests that phonological congruency checking does not constitute a strategy, useful in some cases, but is unintentionally triggered by finding some phonological information common to the prime and the target. For word responses in the lexical decision task, a facilitation effect was observed in the three-phoneme-overlap trials; however, since this effect was not significant in the analysis by subject, it should probably not be given too much credit.

\section{GENERAL DISCUSSION}

Previous evidence on phonological priming in spoken word recognition might be interpreted either as positive, if the absence of an effect in lexical decision reported by Slowiaczek and Pisoni (1986) is attributable to postaccess processes, or negative, if the presence of facilitation in identification in noise that was observed by Slowiaczek et al. (1987) is attributable to a guessing strategy. The ambiguity of the data led us to test phonological priming comparing the shadowing task and the lexical decision task. If some activation of the lexical entry corresponding to the target were produced by a prime phonologically related to the target, then one should expect reaction times to phonologically related word targets to be shorter than reaction times to phonologically unrelated ones. However, in neither of the two experiments of the 
present study did any phonological facilitation result. The now available evidence on phonological priming thus supports the view that phonological activation, if it ever occurs, does not last long enough to affect perceptual processing of the target. On the other hand, in the lexical decision experiments, phonological relatedness resulted in interference on the target with the same lexical status as the prime. This pattern of results was accounted for by postulating the involvement of a postlexical mechanism that mandatorily checks for phonological congruency (this mechanism is discussed further below).

One could still try to keep the phonological priming interpretation of Slowiaczek et al.'s (1987) findings by making the two following arguments. First, one could admit that the absence of an effect in the shadowing task resulted from conflicting facilitation, due to priming, and inhibition, due to competing responses (the prime and the target, though similar to some extent, require different output representations). This interpretation of our data is logically possible, but it is also unparsimonious, and we are thus reluctant to give it any significant weight. Second, one could consider that different patterns of results can be obtained in French and English. Indeed, it has been suggested by Cutler, Mehler, Norris, and Segui (1987) that speech-segmentation procedures may differ in speakers of these two languages. French speakers seem to use a syllabification procedure, whereas English speakers do not show evidence of such a process. The potential relevance of these cross-linguistic differences for the interpretation of our results may be ascertained. Note that, in our experiments, both the two-phoneme- (onesyllable-) and the three-phoneme-overlap conditions provide syllable-priming situations, whereas the one-phoneme overlap does not. If phonological priming in French is associated with the use of the syllable as a unit of lexical access, then we should have found priming effects in the former two conditions, not in the latter one. However, the results obtained in Experiment 2 with the shadowing task do not show any evidence of priming in the onesyllable- and three-phoneme-overlap conditions; moreover, there is no hint of a smaller effect in the onephoneme-overlap condition.

As far as the units issue is concerned, it may be interesting to look at the results obtained for the different overlap conditions with the lexical decision task. Phonological interference effects obtained with this task arise, as we suggest, in Experiment 2 from postlexical processes that take into account different types of comparison between the prime and the target, and in Experiment 1 from both these processes and an attentional mechanism linked to the subjects' expectancies of repetitions. In each case, one can assume that the amount of interference obtained in the different overlap conditions depends on the format of the phonological representations that are involved in those matching operations. More precisely, if the format is syllabic, one may expect as much interference in the one-syllable- as in the three-phoneme-overlap conditions, and greater interference in these two conditions than in the one-phoneme-overlap condition. But if the format is phonemic, then one may expect progressively greater interference from the one-phoneme to the three-phoneme overlaps. The evidence gathered in the present study does not allow a precise suggestion as to the format of the phonological representations responsible for the interference effects, but it is contrary to the notion of a strictly syllabic representation. The statistical analyses made on the results of Experiment 2 indicate that the interference observed on the pseudoword targets was significant for both the one-syllable and the three-phoneme overlaps, with no significant difference between them, and that there was no significant interference for the one-phoneme overlap, thus lending some support to the syllabic format hypothesis. However, the amount of interference looks as if it increased progressively with the number of shared phonemes. Moreover, in Experiment 1, the amount of interference observed on word targets not only was as great in the one-phoneme as in the one-syllable overlaps but, in the first case, it was highly significant. This onephoneme effect should not have been obtained if only syllables were represented. Before leaving this issue, it is important to point out that the present evidence against a strictly syllabic format may concern phonological output representations and not the phonological representations elaborated during input analysis for lexical access, which are usually assumed to be the locus of the effects described by the Paris and Cambridge groups (Cutler et al., 1986; Mehler, Dommergues, Frauenfelder, \& Segui, 1981).

A recent study by Milberg, Blumstein, and Dworetzky (1988) has shown a phonologically mediated semantic priming effect in lexical decision, and thus deserves discussion in the present context. More specifically, the authors found that a pseudoword prime such as GAT or WAT does facilitate lexical decision on a word target such as DOG. This effect is smaller than the semantic priming of DOG obtained with the word prime CAT, but it is nevertheless significant. According to the authors, a pseudoword that is phonologically related to a lexical entry may be "normalized" and processed as an actual lexical entry. This finding is consistent with the sequential search for the best match between the input and a lexical entry that is proposed by the "new cohort model" (MarslenWilson, 1987), in which the search is no longer oriented toward only the initial phonological information, but takes the overall information into account. Milberg et al. (1988) consider as equally possible an alternative explanation in terms of activation of lexical entries as a function of the phonological similarity between the input and the entry. Whether preference is given to an active process such as search or a passive one such as activation, the interpretations contemplated by the above authors all claim that processing of the prime not only leads to its correct iden- 
tification as, say, the pseudowords GAT or WAT, but also allows contact with the lexical entry CAT, at least for a short time. If this were true, then it might be difficult to reconcile Milberg et al.'s finding and our data. The fact that those authors used monosyllabic items whereas we used disyllabic ones, and the fact that overlap concerned the final part of the item in Milberg et al.'s study but the initial part in our study, might not be major reasons for the outcome discrepancy. There is, however, a further explanation of Milberg et al.'s finding. Although these authors have situated the "normalization" of the pseudoword prime at the moment it was processed, it is quite possible that such a normalization only occurred during processing of the semantically related word target. Processing of DOG as dog may have led to reinterpretation of GAT or WAT as cat and, given the semantic relationship between the two lexical entries, to facilitation of the lexical decision. Indeed, backward semantic priming has already been observed in lexical decision (Kiger \& Glass, 1983; Seidenberg et al., 1984), thus making this explanation likely. Should it be repeated that lexical decision is not a pure reflection of lexical access?

The interference effects obtained in the partial phonological overlap conditions with both the shadowing task (Experiment 1) and the lexical decision task (Experiments 1 and 2) is interesting by itself. Indeed, these results show that (1) shadowing is sensitive to attentional factors, and (2) postaccess processes are contained in the lexical decision task. The results obtained here with the lexical decision task are not really in discordance with those of Slowiaczek and Pisoni (1986), since those authors observed nonsignificant tendencies toward the same kind of effect. The interesting aspect of the present results is that the interference effects were observed for word targets with word primes (Experiment 1) and for pseudoword targets with pseudoword primes (Experiment 2). This relationship between the lexical status of the items and the effects of phonological overlap suggests that the decisionmaking mechanism may take into account the phonological relationships between the prime and the target, even though these relationships are completely irrelevant to the task (cf. the more detailed justification of this interpretation in the Discussion of Experiment 1). Semantic, associative, and syntactic congruency factors have already been demonstrated in previous research with the lexical decision task (de Groot, 1985; Forster, 1981; Seidenberg et al., 1984). As noted in the introduction, lexical decision may also be influenced by the congruency between phonology and orthography (Jakimik et al., 1985). The present finding suggests that any kind of relationship occurring frequently in the experimental material may trigger a mechanism that checks for congruency. In our situation, the decision-making mechanism responsible for the lexical decision response is disturbed in selecting the primed response to the target by the finding of a partial phonological discrepancy with the prime.
From a methodological point of view, the present data converge with others to make it clear that a prerequisite to the understanding of information processing should consist of elucidating the levels of processing that are tapped by the specific tasks used in the experiments. In visual word recognition, it has long been recognized that any thorough knowledge of the lexical access process cannot rest only on the data of studies using the lexical decision task. Consequently, for a number of authors, it has become a must to try to validate their results by systematically comparing lexical decision to other tasks, such as naming (see, for instance, Balota \& Chumbley, 1984; Forster, 1981). What our results indicate is that, in the field of spoken word recognition, the shadowing task might fulfill the same kind of validating function as naming.

\section{REFERENCES}

Balota, D. A., \& Chumbley, J. I. (1984). Are lexical decisions a good measure of lexical access? The role of word frequency in the neglected decision task. Joumal of Experimental Psychology: Human Perception \& Performance, 10, 340-357.

Balota, D. A., \& Chumbley, J. I. (1985). The locus of the word frequency effect in the pronunciation task: Lexical access and/or production? Journal of Memory \& Language, 24, 89-106.

Bradley, D. C., Forster, K. I. (1987). A reader's view of listening. Cognition, 25, 103-134.

Cutler, A., Mehler, J., Norris, D., \& Segui, J. (1986). The syllable's differing role in the segmentation of French and English. Journal of Memory \& Language, 25, 385-400.

DE GroOt, A. M. B. (1985). Word context effects in word naming and lexical decision. Quarterly Joumal of Experimental Psychology, 37A, 281-297.

Ellis, A. W. (1982). Modality-specific repetition priming of auditory word recognition. Current Psychological Research, 2, 123-128.

Forster, K. I. (1981). Priming and the effects of lexical and sentence contexts on naming time: Evidence for autonomous lexical processing. Quarterly Journal of Experimental Psychology, 33A, 465-495.

Frauenfelder, U. H., \& TYLER, L. K. (1987). The process of spoken word recognition: An introduction. Cognition, 25, 1-20.

JACKSON, A., \& MORTON, J. (1984). Facilitation of auditory word recognition. Memory \& Cognition, 12, 568-574.

JAKIMIK, J., COLE, R. A., \& RUDNicky, A. I. (1985). Sound and spelling in spoken word recognition. Joumal of Memory \& Language, 24, $165-178$.

KIger, J. I., \& Glass, A. L. (1983). The facilitation of lexical decisions by a prime occurring after the target. Memory \& Cognition, 11, 356-365.

Lorch, R. F., Jr., Balota, D. A., \& Stamm, E. G. (1986). Locus of inhibition effects in the priming of lexical decisions: Pre- or post lexical access? Memory \& Cognition, 14, 95-103.

Marslen-Wilson, W. D. (1985). Speech shadowing and speech comprehension. Speech Communication, 4, 55-73.

Marslen-WiLson, W. D. (1987). Functional parallelism in spoken word-recognition. Cognition, 25, 71-102.

Marslen-Wilson, W. D., \& Welsh, A. (1978). Processing interactions and lexical access during word recognition in continuous speech. Cognitive Psychology, 10, 28-63.

Mehler, J., Dommergues, J.-I., Frauenfelder, U., \& Segui, J. (1981). The syllable's role in speech segmentation. Journal of Ver bal Learning \& Verbal Behavior, 20, 298-305.

Milberg, W., Blumstein, S., \& Dworetzky, B. (1988). Phonological factors in lexical access: Evidence from an auditory lexical decision task. Bulletin of the Psychonomic Society, 26, 305-308. 
Morton, J. (1970). A functional model for memory. In D. Norman (Ed.), Models of human memory (pp. 203-254). New York: Academic Press.

NeELY, J. H. (1977). Semantic priming and retrieval from lexical memory: Roles of inhibitionless spreading activation and limitedcapacity attention. Joumal of Experimental Psychology: General, 108, 226-254.

POSNER, M. I., SNYDER, C. R. (1975). Attention and cognitive control. In R. L. Solso (Ed.), Information processing and cognition: The Loyola symposium (pp. 55-85). Hillsdale, NJ: Erlbaum.

Radeau, M., \& Morais, J. (1989). The effect of the uniqueness point in shadowing spoken words. Manuscript submitted for publication.

Seidenberg, M. S., Waters, G. S., Sanders, M., \& Langer, P.
(1984). Pre- and postlexical loci of contextual effects on word recognition. Memory \& Cognition, 12, 315-328.

Slowiaczek, L. M., Nusbaum, H. C., Pisoni, D. B. (1987). Phonological priming in auditory word recognition. Journal of Experimen tal Psychology, 13, 64-75.

Slowiaczek, L. M., \& Pisoni, D. B. (1986). Effects of phonological similarity on priming in auditory lexical decision. Memory \& Cognition, 14, 230-237.

TrÉsor de la Langue Française (1971). Dictionnaire des fréquences. Paris: Klincksieck.

(Manuscript received October 3, 1988; revision accepted for publication March $31,1989$.

\title{
Announcement
}

\author{
19th Annual Meeting of the Society for Computers in Psychology \\ Atlanta, Georgia \\ November 16, 1989
}

The 19th Annual Meeting of the Society for Computers in Psychology will be held at the Hyatt Regency Hotel in Atlanta, Georgia on November 16, 1989. As usual, this meeting will feature papers on applications of computers to all areas of psychology-experimental, clinical, and educational.

For further information, contact Paula Goolkasian, Department of Psychology, University of North Carolina at Charlotte, Charlotte, NC 28223. 